\title{
Chapter 9 \\ From Wastescapes Towards Regenerative Territories. A Structural Approach for Achieving Circularity
}

\author{
Libera Amenta (i) and Arjan van Timmeren (i)
}

\subsection{Introduction: Circular Metabolisms and the Regeneration of Wastescapes}

Reporting the research developed within the European H2020 research project REPAiR, the definition of wastescapes, provided in this study, builds upon work for two main cases: the metropolitan areas of Amsterdam (The Netherlands) and Naples (Italy).

The most vulnerable spaces of urban and peri-urban areas could be found in the so-called 'wastescapes' (Amenta, 2019; Amenta \& van Timmeren, 2018; REPAiR, 2017a), seen as abandoned areas, or discarded territories and, at the same time_-'moving towards a regenerative perspective' (Amenta et al., 2019) — as ecoinnovative resources to improve the socio-ecological value of our contemporary territories. Wastescapes could be defined as 'unresolved territories', and as: 'privileged places for the proliferation of degradation phenomena that affect the environment and human well-being' (Cerreta et al., 2020, p. 1).

The understanding of neglected areas as wastescapes, meaning as the leftover spaces, thus the conceiving of them as waste or dross of the dynamics of the 'urban metabolism', builds on the American literature on 'Drosscape' by Alan Berger (Berger, 2006a, 2006b). The sociological perspective on wastescapes, as well as on urban metabolism, as reviewed by McDonald \& Patterson, 2007, is a reminder of the irrationality of societies in the face of material (including water and nutrients) and energy flows. However, one important (positive) difference is crucial to be

\footnotetext{
L. Amenta $(\varangle)$

Department of Architecture (DiARC), University of Naples Federico II, Naples, Italy e-mail: libera.amenta@unina.it
}

\section{Amenta $\cdot$ A. van Timmeren}

Department Od Urbanism, Chair of Environmental Technology and Design, Delft

University of Technology (TUDeflt), Delft, The Netherlands

e-mail: a.vantimmeren@tudelft.nl 
mentioned here: human settlements are able to adapt to environmental conditions. In contrast to many natural entities, a human settlement has the ability to be self-aware of its actions (and the effects of those actions), and adjust behaviour if necessary (van Timmeren, 2014).

This positive approach has been applied to wastescapes in the European Horizon 2020 project 'REPAiR-Resource Management in Peri-urban Areas: Going Beyond Urban Metabolism', in an attempt to understand 'wastescapes' as 'resourcescapes', meaning as potential areas to be regenerated for multidimensional socio-environmental purposes. This is founded on the awareness of the actual context of resource scarcity and of the necessity to pursue the European agenda to move towards zero waste, zero emissions and the achievement of more resilience to systemic disruptions. All of this, with the aim to achieve a more inclusive Circular Economy (Ellen MacArthur Foundation, 2015, 2017). The REPAiR project focused on the transformation of the actual (mostly) linear Urban Metabolism of six PeriUrban European Areas towards a Circular one, by closing the loops of resource flows, and by recovering the values of the underused or unvalued wastescapes. Wastescapes can be the result of two simultaneous processes of growth (urban dispersion and fragmentation) and contraction of cities (shrinkage, abandonment) (Amenta, 2015). To illustrate, they can be the result of changes in the economy and land use, due to for instance technological innovation and resulting structural obsolescence of buildings and infrastructures, demographic change or climate-related issues. Wastescapes could also be seen as the outcome of the 'metabolism of risk' (Russo \& Attademo, 2020), as the emblem of the loss of the ecological balance between citizens and landscapes.

\subsection{Peri-Urban Living Labs (PULLs) as a Collaborative Methodology for the Sustainable Regeneration of Wastescapes}

Wastescapes are complex territories that differ case by case, typified by site-specific features: pollution, abandonment, lack of functions for certain areas, etcetera. Their condition of wastefulness involves different social, economic, spatial and environmental aspects. Due to their complex nature, their regeneration requires systemic approaches with the involvement of all the stakeholders.

Wastescapes have been defined within the research project REPAiR (REPAiR, 2017a, 2018c) as a combination of Drosscapes (Berger, 2006a) and Operational Infrastructures of Waste (Brenner, 2014). The first category of Drosscape includes degraded and/or neglected territorial resources related to subsoil (polluted soils, bare soils, artificial soils); water (water bodies, banks, shores, tanks, plants, flooding zones); land use (abandoned spaces, vulnerable lands); buildings (vacant and underused buildings and settlements, unauthorized, confiscated buildings and informal 
settlements); and infrastructures (dismissed or unused infrastructures and/or facilities). The second category, namely Operational Infrastructure of Waste, includes all the still performing facilities for waste management (storage, treatment, transportation/infra, etc.) (REPAiR, 2017a, p. 29).

The presented research aims to show first of all that wastescapes go beyond brownfields, comprising the diverse aforesaid grouping, and secondly that they can be considered a spatial resource, crucial to be included in strategies of action towards a circular economy. The spatial regeneration of wastescapes-including the two abovementioned categories-involves an integrated rethinking of the structure of periurban areas, its relations and functionalities, as an 'in-between' territory comprises among urban and rural. Peri-urban territories could be particularly affected by the problem of wastescapes, as they are spatially fragmented territories, characterized by mixed uses, and constituted by different function spread in the areas in-between urban and rural landscapes. Again, important to note here is that, within this context, circularity is understood beyond the sole material resource management, deepening the spatial implications of a circular management of resources, investigated at the urban and territorial scale.

The regeneration of wastescapes can be addressed as an innovative approach for sustainable developments, with an ecosystems services perspective that builds on the idea to re-build on cities as cradles of encounter and shared (eco)services. On the one hand, it is necessary to focus on the existing buildings and infrastructures, by valorizing and recycling wastescapes; on the other hand, policies on urban densification, such as infilling require strategically incorporated regeneration processes of wastescapes. Densification here, is not necessarily understood as spatial densification alone. It can also be referred to densification of different kinds of use, as ecosystems services, which could support the accessibility for everyone to (re)new(ed) public (open) spaces or facilities. Due to the need to find space as a result of lower densities of use of space - based on sustainable concepts (van Timmeren, 2006) - at the same time, this process can help realize the transition towards more sustainable, liveable and just environments as well as to possible ways to finance these. Within the new reality of a (post) Covid-19 world, a clear need for a wider availability of green areas, parks and public space and facilities in general has been shown to be crucial for health and well-being. This includes proximity to nature, something that is not always as obvious in today's cities, and — even if is present—-denied by the restrictions imposed to contrast the pandemic. Often, precisely as a result of (spatial) densification strategies. Therefore, in particular a smarter use of available, under-used or unused areas, like wastescapes is crucial to fill this gap.

Peri-urban areas are characterized by diffused settlements (Wandl, 2019) providing the post-pandemic resilient infrastructures at 'the right distance of the urban archipelago' (Gabellini, 2018, p. 29. Authors' translation in English from Italian). If done in the right way, they could be transformed into new infrastructures for urban sustainability and circularity: linked to green and environmental networks 
which could densify the dispersion and open gaps in the dense urban areas, increasing porosity and voids (Pavia, 2015).

To cope with the increasing complexity of European peri-urban areas, REPAiR implemented a 5-phases methodology based on 'Co-Creation' developed and tested in six Peri-Urban Living Labs (PULLs). This 'Co-Creation' methodology applied in these PULLs comprises the following steps: 'Co-Exploring', 'Co-Design', 'CoProduction', 'Co-Decision' and 'Co-Governance' (Amenta et al., 2019; REPAiR, 2017 b 2018c). It has been implemented and tested with the main objective to elaborate Eco-Innovative Solutions and Eco-Innovative territorial Strategies which can enable decision-makers to better deal with waste management questions, including the spatial regeneration of wastescapes. As they are based on the six models of the Geodesign Framework developed by Steinitz (2012), ${ }^{1}$ the five steps work in an iterative and integrated way. Within this approach, wastescapes are treated in a similar way as material waste in the value chain of the metabolic flows, to achieve more circular territories.

\subsection{REPAiR Peri-Urban Living Lab (PULL) Methodology and Wastescapes Characterization in the Cases of Amsterdam and Naples}

The wastescapes identified in the peri-urban territories of two of the six REPAiR cases, viz. Amsterdam and Naples Metropolitan Areas, are the spaces where challenges related to waste management are intertwined to spatial (e.g. fragmentation and accessibility), environmental (e.g. nuisance zones, pollution and degradation), and functional (e.g. malfunction and ownership) problems. For these wastescapes and their regeneration, REPAiR developed an interdisciplinary and multiscale approach, based on a collaborative process, aiming to manage different challenges at the same time through the development of Eco Innovative Solutions (REPAiR, 2018a, 2018b).

Through the stated 5-phase Co-Creation process implemented in the REPAiR PULLs (Amenta et al., 2019; REPAiR, 2018c) it was possible to cope with such complexity. It also allowed the collaboration of all stakeholders, which was crucial at each stage of the development process (Amenta \& van Timmeren, 2018).

The first step of the REPAiR PULL methodology was the 'Co-Exploring' phase. ${ }^{2}$ It aimed to develop an integrated knowledge framework and a complete description of the case study areas, which includes spatial investigations as well as all the studies

\footnotetext{
${ }^{1}$ For more information on the 'co-creation' PULL methodology and the relation with the Geodesign framework visit the REPAiR webpage at the following link: http://h2020repair.eu/co-creation/.

${ }^{2}$ For an extensive explanation of the PULL methodology, organized in 5 phases, see the two REPAiR Deliverables: "Deliverable 5.1 PULL Handbook" and "Deliverable 5.4 Handbook how to run a PULL, which could be retrieved at this link: http://h2020repair.eu/project-results/project-rep orts/.
} 
related to the processes for managing material and territorial resources relevant for each area(s) of focus. Specifically, in this phase, a determined setup of stakeholder subgroups altogether were addressing the quest to identify and map the specific wastescapes in the area of subject.

This phase included an iterative process of fieldwork and meetings with local actors-differentiated case by case-e.g. representatives of the public sector and decision-makers, citizens' associations, small enterprises, and so on. The stakeholders' needs, challenges, problems and objectives also have been categorized in this phase. Overview maps were made by researchers based on the input (and finishing up of determined characterizations for the specific metropolitan area of focus), then they were verified in the PULL workshops by the local stakeholders; this activity was crucial to update the maps which were adjusted according to the stakeholders' feedback. Among the wastescapes mapped in the REPAiR case studies, and validated as a second iteration by the key local stakeholders in the PULL settings, the array of outcomes is quite rich: e.g. there are polluted and abandoned soils, but also all the infrastructures for the waste management.

This first step in the PULL methodology started in Naples Metropolitan Area, where both key resource flows as well as wastescapes were identified and mapped. In particular, the latter can be characterized by spatial and environmental issues intertwined with social problems and often with informal activities related to waste management, altogether generating complex geographies of waste.

When zooming out, it becomes clear that a large presence of wastescapes could be found in the Eastern parts of Naples, which represent the historical industrial and productive areas of the city. Here wastescapes are a result of obsolescence (mostly resulting from the industrial decline), but also due to their monofunctionality as highly specialized areas where there is no functional mix at smaller scales, and spatial fragmentation at metropolitan scales (Castigliano et al., 2020). On top of this, in East Naples, wastescapes are framed as 'un-named spots to which people do not belong anymore' (Russo, 2012).

As a next step, the mapping experiments and methodology started in Naples were further developed in REPAiR's second pilot case, viz. Amsterdam Metropolitan Area (AMA). Due to another culture of policies and land use planning (among others), in this area, wastescapes had quite different characteristics, as they were mostly observed along large infrastructures (e.g. highways, the port and airport), like for instance, wasted territories as a result of legal nuisance zones of Schiphol Airport, wind turbines and other infra, and industries in the port. In the Amsterdam Metropolitan Area, the identification and drawing up of wastescapes at all has been unexpected for involved stakeholders, showing that even in spatial contexts known to be (re)developed and planned already many times such areas exist more often, and with a larger share then imagined.

After several reiterations carried out in a series of REPAiR PULL workshops, in both the Amsterdam and Naples Metropolitan Areas, different types of wastescapes could be determined, each of which related to the specificities of the places, its use and governance. In this first phase wastescapes also were identified for their promising 
hidden value and possible transformability; thus, wastescapes have been confirmed to typify potential resources for urban and territorial regenerations.

In the second step of the REPAiR PULL methodology, the Co-design phase, local teams in the six case studies jointly developed site-specific Eco-Innovative Solutions (EIS) and strategies. This was done through academic workshops and seminars with researchers and students, over and above within PULL meetings and workshops with stakeholders. In this phase, experiments and research took place with the aim to assess the status quo of the area of focus and to further outline specific challenges and problems, in order to refine EIS and their functioning in the specific contexts. Thus, challenges and problems relevant to the local contexts were defined in order to look for the most suitable EIS supporting their regeneration. Next, the resident stakeholders helped to identify the basic characteristics that the solution/strategy aimed for must have to create lasting change in the particular context. To do so, each of the six REPAiR case studies focused on:

- Prioritizing problems and resulting objectives,

- Development and refinement of initial ideas to achieve these objectives, towards the creation of eco-innovative solutions and strategies.

An important part of this phase concerned the identification of so-called 'enabling contexts' for an easier and even faster possible implementation of the chosen solutions (e.g. publicly owned spaces). These 'enabling contexts' have been defined 'as specific locations within the focus area that are more suitable for developing the eco-innovative solutions and strategies [...] system of areas in which the experimentations can be more easily applied and where the general process of regeneration can be tested and implemented as of prime importance' (REPAiR, 2018d, p. 27).

For instance, in the case of Amsterdam, main enabling contexts were classified as the areas with:

- the highest concentration of wastescapes;

- the highest index of social stress (low-income population, unemployment, low education, non-active working population);

- the highest concentration of unavoidable and avoidable (food) waste collected as residual waste, per person, per year;

- the location of companies in which the largest share of total tonnes of (food) waste are produced;

- most urban expansion and transformation areas (REPAiR, 2018d, p. 99).

In continuation, in the third phase of the REPAiR PULL methodology, Coproduction, for each of the six case study areas local teams-in which all key stakeholder groups were represented-developed a catalogue of site-specific Eco-Innovative Solutions (EIS) for their cases.

This phase is considered crucial for the identification of suitable strategies for the transition towards sustained circularity within these peri-urban areas of focus. Crucial here is too that, at the same time, the promoting innovation processes to do so help fill in a sound economic business case. 
In total, the REPAiR project developed over one hundred Eco-Innovative Solutions, connected to the cases, and being a support of circularity and for the regeneration of the pinpointed wastescapes. ${ }^{3}$

Focusing on wastescapes, and the two main cases, Naples and Amsterdam, inside the Metropolitan Area of Naples (MAN) wastescapes appear with quite different characteristics. For instance, one of the most challenging peri-urban areas under development is located surrounding the high-speed train station of Naples-Afragola, towards Acerra, and Pomigliano d'Arco. This area contains a number of exemplary wastescapes and was given high priority by the stakeholders present in the local PULL workshops, as wastescapes are characterized by illegal activities, often also related to waste management, to territorial 'fragmentation' and pressure on the livability of the areas in general. For this particular sample area, multiple wastescape maps and wastescape category-sheets were produced. These data subsequently were improved based on case-specific knowledge of citizens, public authorities and other stakeholders within a series of PULL workshops. The solutions identified in this phase also stressed the importance to make them available to the local communities. This, as some of them concern misused areas and even illegal settlements. Outcome of the PULLs here was that, by connecting them actively to the transition, to the regeneration of the wastescapes, they could be given potential to become new, formalized public spaces, which at the same time support circularity, inclusiveness and improve overall livability. To support this further, it resulted to be of great help that in the PULLs of Naples cultural associations also have been involved. This was done so in order to provide a potential 'problem owner', that would be apt to manage public areas, and by doing so increase citizens' sense of belonging to this territory (Amenta \& van Timmeren, 2018; REPAiR, 2018b).

In the other main pilot case, Amsterdam Metropolitan Area (AMA), also wastescapes were identified in this Northern part of the larger 'Randstad' area, in the territory comprises between the two provinces of North-Holland and Flevoland and 15 municipalities. Here, more coherence was found, as most of them were related to legal restrictions for use (be it due to nuisance or pollution, of all kind). For instance, the areas around the Schiphol airport were identified as challenging wastescapes, as they are both nuisance zones subject to development restrictions as a result of noise and safety regulations, as well as areas of importance, as being part of important green, unbuilt areas supporting a positive effect on the urban heat island (UHI) of the Western parts of the city. Wastescapes identified in this case, were also related to the harbour and diminishing industrial areas. For the regeneration of these wastescapes, trust and collaboration among stakeholders 'under siege' of land use and functional change clearly resulted to be necessary. The PULLs therefore also functioned as platforms where public and private actors cooperate to respond to a common goal set, here circular area development. For this purpose, the stakeholders of the AMA PULL included researchers, local government representatives, policymakers, as well as local business representatives. Again, a series of collaborative PULL workshops

\footnotetext{
${ }^{3}$ For more info visit the section of the REPAiR website on the Eco-Innovative Solutions: http://h20 20repair.eu/eco-innovative-solutions/.
} 
were held with the aim to develop EIS for all kinds of circular concepts in the AMA (Amenta \& van Timmeren, 2018; REPAiR, 2018b). To illustrate, for example, some of the solution paths proposed are related to the desire to overcome the problem of construction restrictions for the sake of circular material use and concepts, as well as for the regeneration of wastescapes in the (nuisance) areas around both port and Schiphol airport; they are often related to improved flexibility regarding too stringent regulations. For instance, by applying new ways of regulations based on measuring instead of calculation of noise nuisance. This, as traditionally the noise footprint of aeroplanes is computed by using models which calculate the equivalent sound pressure levels. To shorten the calculation time of such models, buildings and urban objects are neglected. The large computational overhead of diffraction points around edges, and reflections between walls, would make the calculations too time-consuming. The concept proposed in the PULLs related to these specific wastescapes builds upon so-called adaptive noise levels, as recent studies showed that the existing calculation models, which legally define them as nuisance zones, give an over-simplified image compared to reality, in which buildings yield a substantial reduction or amplification of aircraft noise. Another solution brought up in the PULLs related to these specific wastescapes was the possible increase of their ecological value, by developing a natural corridor within these airport noise contour areas. And by doing so, building upon further expansion to the previously stated function of UHI reduction in the built areas at lee side (of prevailing winds), and by doing so this could be a way to deal with the relative malfunctioning of these areas.

The fourth phase of the REPAiR PULL methodology is the Co-decision phase and it builds upon the results of the previous phases. In this phase, the Eco-Innovative Solutions (EIS) and elaborated strategies were shared with a wider public, also thanks to the potentialities of the GDSE tool, with the aim to feed-in to the decision-making process in general and the overall engagement of users and all other relevant stakeholders. In this phase, solutions and strategies were potentially becoming a means for reference among different actors for triggering and supporting the actual regeneration of the wastescapes in the case-study areas. In this stage, actual public programs and urban planning policies were discussed with all stakeholders within the next series of PULLs, to understand to what extent it is possible to actually implement the identified solutions and strategies. The Co-Decision phase was also useful to verify the possibility for potential implementation of the solutions/strategies, checking the existing policies and their flexibility; to this aim, existing local initiatives have been taken into consideration and discussed in the workshop sessions. In the very last phase of the project, due to the spread of the Covid-19 pandemic, the richness of the interactions possible during the initial PULL meetings was substantially reduced by the necessity to only have online meetings.

The final phase of the REPAiR PULLs methodology concerns Co-governance. It aims to secure and manage the actual implementation of solutions and strategies (and objectives set) related to the regeneration of the aforenamed wastescapes in the different case studies. Also, to adapt solutions to a possible transferability to different case studies elsewhere. For the transferability of solutions and strategies it is crucial 
to define which could be the basic principles that constitute them and how these could be applied by certain adaptions, based on different territorial realities.

Co-governance should be considered as one of the most interesting phases of a PULL, since it refers to the tangible execution of the solutions/strategies, which could be able to modify the functionality of the territorial metabolism, meaning its flows (AS MFA), its human ecology, its urban political ecology, and its landscapes ecology (Grulois et al., 2018). However, in the REPAiR project, this phase was not developed further, since it was not included in the workplan. Nevertheless, some of the case studies have been able anyway to start to apply the REPAiR developed solutions/strategies in some local initiatives and projects. Therefore it is fair to state that the whole PULL process indeed facilitated advantageous stakeholder interactions, which has led them to continue working together also beyond the REPAiR project.

\subsection{Discussion and Conclusions: How to Regenerate Wastescapes in Peri-Urban Areas}

The presented research, which builds on the REPAiR research project results, starts from the fact that the contemporary society is still based on unsustainable linear models of growth and consumption-involving the depletion of increasingly scarce material and territorial resources, and producing high amount of waste and wastescapes. The latter, which often concern peri-urban landscapes, are slowly metabolized by urban systems, generating pollution and overall unuse and inefficiency.

The concept of landscape-within the definition given by the European Convention on Landscape (Council of Europe, 2018) - is an important component to take into account when aiming for transformations towards a more circular society. More often than not, they can be characterized by wastefulness generated by unhealthy metabolisms, as well as spatial decline and fragmentation. Centralized infrastructure provision, a legacy of the twentieth century, facilitates linear (urban) metabolism and leads to ecological overshoot. Over-consumption is possible because of inherited resources: fossil fuel, fertile land, clean water and even oxygen in the atmosphere. Wastescapes are the result of linear urban metabolic flows and unsustainable growth which generated, for several reasons, the so-called 'peripherical areas'. The latter are urban areas that have been treated for a long time as backsides. They are defined as 'peripheries' not only for their actual distance to the urban core (which sometimes is irrelevant being in strategic positions linked to the city cores) but also for both their residual function and image, of which the latter is fixed in the common perception of citizens (Berruti, 2019, p. 21).

At the same time, gradual or sudden disruptions, such as climate change and criticalities as a consequence of pandemic or other disruptions, are worsening this disequilibrium by challenging urban settlements and the use of nature and natural areas. Altogether they are shedding light on their vulnerability and consequences 
to health, well-being and, in the end, even economic potentials. For instance, the complex situation as a result of the global Covid-19 pandemic is contributing to inverting the traditional point of view on the relevance of the built environment, conversely stressing - once again - the significance of open and natural areas. The open/accessible (preferably green) public spaces to be found in urban and peri-urban environments, which could be used for leisure activities, to achieve a healthier model of life, especially within this time characterized by the sanitary emergence, have regained their value which surpasses significantly that of monetary value alone. At the same time, the very being of wastescapes forms an obstruction to such values. Therefore, and in order to achieve a real transition towards a circular and sustainable future, active regeneration will be necessary to implement an approach that refuses the very concept of waste-in its wider significance - thus including wastescapes and adds new values in a multiscalar circular ecosystem. Up until now, circular economy was generally adopted by governmental policymakers with the main goal to protect the environment and reduce greenhouse gas emissions. In addition to that, a more systemic solution is needed, which puts all three dimensions of sustainability-social, economic and environmental—at the centre of societal shift. Such an integrated social inclusive approach, together with the reduction of the demand of resources and a shift to circularity-or so-called multiple value creation-could secure the sustainability of contemporary living models, functioning without overcoming the planetary boundaries and stay within the so-called 'doughnut' of a 'safe and just space for humanity' (Raworth, 2017). The doughnut consists of two concentric rings, an inner ring and an outer ring. The inner ring represents 12 social foundations, derived from the Sustainable Development Goals (SDGs), needed for a society to thrive (ibid., 2017). The outer ring represents the nine ecological planetary boundaries, developed by Rockström et al. (2009). Doughnut Economics (DE) urges us to keep challenging ourselves to take heed of the planetary system in its entirety. It reminds us of the importance of human socio-cultural development and our ability to organize. It values diversity, dynamics, scale and complexity of the interacting systems. It argues for distributive and regenerative capacity building. And although Raworth recognizes that growth is important, DE shows that there are various ways of growing that go beyond GDP growth or an increase in Gross Value Added (Raworth, 2017). In this way, other values (then monetary) are put forward too. The resulting holistic, transdisciplinary and inclusive, comprehending a bottom-up development based on a collaborative approach, can, in sum, form a robust systemic solution and highly adaptive model that allows for societal and environmental change.

The premise to be able to successfully implement an approach similar to DE, adapted to regenerate wastescapes, needs to be based on a deep understanding of the local contexts, which in this paper has been illustrated with the cases analysed in the co-exploring phase of the REPAiR PULLs. This phase is crucial for getting a deep understanding of the complex problems intrinsic in wastescapes, and by mapping of underlying processes and problems of such case study areas, within larger peri-urban territories in metropolitan regions. This forms the basis for change models.

In the presented REPAiR project, the six European cases of focus concerning metropolitan areas and in particular peri-urban territories, or so-called 'territories 
in between' (Wandl, 2019). These peri-urban areas contain the vast majority (in size and number) of wastescapes. At the same time, however, among the numerous potentials of these peri-urban areas, the mixed-use combined with relative lower densities and large availability of space, have also been determined as a potential starting point for further developments. In particular related to sustainability and circularity, which concepts/solutions in general can be characterized by their relative larger spatial footprints (or lower so-called performance densities). These solutions, however, also can be combined, into ecosystems services. At the same time, the concepts of sustainability and circularity are also related with the need to reinterpret the numerous infrastructural networks (and overall network geometry, or architecture). Peri-urban areas and territories-in-between are characterized by all these different kinds of infrastructures (Wandl, 2019), which — through the overlapping of new layers - often makes it difficult in (land-use) planning to establish healthy relationships with the (underlying) landscape, while generating spatial fragmentation and loss of multiscalar ecological networks supporting ecosystems and habitats (Tjallingii, 1996). Through the presented systemic and multidisciplinary approachwhich implementation could be supported by the involving key stakeholders in the integrated methodology of Peri-Urban Living Labs - this research aims to find a renewed equilibrium inside these peri-urban areas and beyond, in their interrelated networks at the metropolitan scale. With the aim to regenerate and re-appropriate the different wastescapes inside these peri-urban areas as new public (open) spaces and regenerative territories, within a $\mathrm{CE}$ and DE approach. This approach is in line with the concepts of Industrial Ecology and Regenerative Design thinking of taking nature as a role model, where processes run on the available (usually low exergetic) resource flows. The circular or panarchy-based processes are characterized by 'low exergy design' which can strengthen the systems, methods and tools used for organizing, operating and supervising the urban environment, while minimizing the negative impacts of these urban areas on ecological cycles at all levels, creating efficient urban systems. Here, regenerative design is defined as 'human made interventions and systems (buildings, urban spaces, infrastructure etc.) that contribute to ecological, social, and cultural health in various holistic and interconnected ways [...] ensuring that the functioning of the built environment leads to positive outcomes in a biological sense. One way to conceive of this is to devise ways to work towards the provision of regulating, supporting, and provisioning ecosystem services. [...] Ecosystems remain the best-known example of sustainable organization of life on this planet. It is logical therefore to try to understand, and if possible, to emulate how organisms and ecosystems work and what they do in the pursuit of the creation of a regenerative human urban habitat' (Zari \& Hecht, 2020, p. 3). If elaborated in this regenerative design way, wastescapes become spaces that include novel urban ecosystem services that support circular and sustainable urban systems. The regeneration of wastescapes then represents an opportunity for increasing circularity, as they take panarchy as a starting point, possibly even resilience in general, and human wellbeing through improved opportunities for a better quality of life, including all kinds of undervalued socio-ecological qualities, such as biodiversity and inclusiveness (DE). 
At larger scale levels, well designed and interrelated regenerative territories originating from former wastescapes in this way could work as an interrelated ecological and social infrastructure.

To test and achieve this, within the EU Horizon 2020 REPAiR project, researchers, designers and local stakeholders of six peri-urban European areas have been working towards the achievement of a Circular Economy supporting methodology and tool, or Geodesign Decision support Environment (GDSE). This entailed that in dedicated Peri-Urban Living Labs (PULLs) all over Europe, a digital geodesign tool, extensive open-source data sets and eco-innovative solutions and strategies (EIS) were created and made available to support (validated) decision-making processes towards a more circular society within designated, often complex, spatial contexts. ${ }^{4}$ To move towards regenerative territories concrete eco-innovative solutions and strategies were developed and tested with key stakeholders for the so-called 'enabling contexts' identified within the Peri-Urban Living Labs.

As a next step and scale-up, the stated solutions (and methodology) need to be tested in other contexts, as well as pilots implemented to validate the final two steps of the PULL methodology developed.

The bottom line is that technical solutions for the recovery of material resourcesformerly known as waste-should be interconnected with more site-specific spatial strategies, preferably first within the many existing wastescapes.

Very often the REPAiR experiments have been slowed down due to the strict local regulations and overall complexity of area (re)development and regeneration. For this reason, an integrated and multidisciplinary approach resulted to be crucial. In this perspective, new forms of collaborative and distributed governance, based on private-public partnerships, and integrating bottom-up and inclusive actions seem to be the next step for the actual transition towards regenerative territories. In this framework, experimentations and innovations should be focusing primarily on the well-being and physical/mental health of people.

Acknowledgments Thanks to the whole REPAiR Team. In particular to UNINA and TUDelft Research Teams.

Author Contributions All the parts of this chapter have been written and approved by both the authors: L.A. and A.v.T.

Funding This research is done within the framework of the European Horizon 2020 funded research 'REPAiR: REsource Management in Peri-urban AReas: Going Beyond Urban Metabolism'. This project has received funding from the European Union's Horizon 2020 research and innovation programme under grant agreement No. 688920. This work reflects only the author's view. The Commission is not responsible for any use that may be made of the information it contains.

\footnotetext{
${ }^{4}$ For more detailed information on GDSE please visit the REPAiR website at the following link: http://h2020repair.eu/gdse-software-package/.
} 


\section{References}

Amenta, L. (2015). Reverse land: Wasted Landscapes as a resource to re-cycle contemporary cities. University of Naples Federico II.

Amenta, L. (2019). beyond WASTESCAPES opportunities for sustainable urban and territorial regeneration. TU Delft Open.

Amenta, L., Attademo, A., Remøy, H., Berruti, G., Cerreta, M., Formato, E., Federica Palestino, M., Russo, M. (2019). Managing the transition towards circular metabolism: Living labs as a co-creation approach. Urban Planning, 4(3), 5-18. https://doi.org/10.17645/up.v4i3.2170.

Amenta, L., \& van Timmeren, A. (2018). Beyond wastescapes: Towards circular landscapes. Addressing the spatial dimension of circularity through the regeneration of wastescapes. Sustainability, 10(12), 4740. https://doi.org/10.3390/su10124740.

Berger, A. (2006a). Drosscape: Wasting land in Urban America. Princeton Architectural Press.

Berger, A. (2006b). The Drosscape: The landscape urbanism reader (pp. 198-217). Princenton Architectural Press.

Berruti, G. (2019). Fuori norma. Percorsi e ragionamenti su urbanistica e informale. INU Edizioni.

Brenner, N. (Ed.). (2014). Implosions/explosions: Towards a study of planetary urbanization. Jovis.

Castigliano, M., De Martino, P., Amenta, L., \& Russo, M. (2020). Reinventing wastescapes in port cities: A resilient and regenerative approach to plan naples at the time of logistics. BDC. Bollettino Del Centro Calza Bini, 20(2), 261-276. https://doi.org/10.6092/2284-4732/7555.

Cerreta, M., Mazzarella, C., Spiezia, M., \& Tramontano, M. R. (2020). Regenerativescapes: Incremental evaluation for the regeneration of unresolved territories in East Naples. Sustainability, 12(17), 6975. https://doi.org/10.3390/su12176975.

Council of Europe. (2018). Council of Europe landscape convention. Retrieved November 19, 2018, from https://www.coe.int/en/web/landscape.

Ellen MacArthur Foundation. (2015). Growth within: A circular economy vision for a competitive europe.https://www.mckinsey.de/files/growth_within_report_circular_economy_in_europe.pdf.

Ellen MacArthur Foundation. (2017). What is the circular economy? Retrieved April 2, 2020, from https://www.ellenmacarthurfoundation.org/circular-economy/what-is-the-circular-economy.

Gabellini, P. (2018). Le mutazioni dell'urbanistica : principi, tecniche, competenze. Carocci editore.

Grulois, G., Tosi, M. C., \& Crosas, C. (Eds.). (2018). Designing territorial metabolism metropolitan studio on Brussels, Barcelona, and Veneto. JOVIS Verlag GmbH.

McDonald, G. W., \& Patterson, M. G. (2007). Bridging the divide in urban sustainability: From human exemptionalism to the new ecological paradigm. Urban Ecosystems, 10(2), 167-167. https://doi.org/10.1007/s11252-007-0021-z.

Pavia, R. (2015). Il passo della città. Donzelli Editore. https://www.donzelli.it/libro/978886843 1693.

Raworth, K. (2017). Doughnut economics : Seven ways to think like a 21st-century economist.

REPAiR. (2017a). Introduction to methodology for integrated spatial, material flow and social analyses REPAiR Deliverable 3.1. EU Commission Participant portal (Grant Agreement No. 688920). https://doi.org/10.4233/uuid:af2e252f-e8ed-472e-a4e8-c4bb4285522e.

REPAiR. (2017b). PULLs handbook REPAiR deliverable 5.1 EU Commission participant portal (Grant Agreement No. 688920). https://doi.org/10.4233/uuid:321f152a-0fe7-4125-bb98-c8c253 e5b39f.

REPAiR. (2018a). D5.2 Catalogue of solutions and strategies for Amsterdam (Grant Agreement No. 688920). EU Commission Participant portal.

REPAiR. (2018b). D5.3 Eco-innovative solutions Naples (Grant Agreement No. 688920). EU Commission Participant portal. Retrieved from http://h2020repair.eu/wp-content/uploads/2019/ 10/Deliverable-5.3-Eco-Innovative-Solutions-Naples.pdf.

REPAiR. (2018c). Handbook: How to run a PULL Deliverable 5.4 (Grant Agreement No. 688920). EU Commission Participant portal. 
REPAiR. (2018d). Process model for the two pilot cases: Amsterdam, The Netherlands \& Naples, Italy (Grant Agreement No. 688920). Deliverable 3.3. EU Commission Participant portal. https:// doi.org/55988e03-ea52-406d-a18f-57ff00630fbd.

Rockström, J., Steffen, W., Noone, K., Persson, A., Chapin, F. S., Lambin, E., Timothy, M. L., Scheffer, M., Folke, C., Joachim Schellnhuber, H., Nykvist, B., de Wit, C. A., Hughes, T., van der Leeuw, S., Rodhe, H., Sörlin, S., Snyder, P. K., Costanza, R., Svedin, U., ... Foley, J. (2009). Planetary boundaries: Exploring the safe operating space for humanity. Ecology and Society, 14(2).

Russo, M. (2012). Napoli verso oriente: un laboratorio di futuro. In R. Michelangelo \& R. Lucci (Eds.), Napoli verso oriente. CLEAN.

Russo, M., \& Attademo, A. (2020). Il metabolismo del rischio. In Geografie del Rischio. Nuovi paradigmi per il governo del territorio. Donzelli Editore.

Steinitz, C. (2012). A framework for geodesign. changing Geography by design. Esri Press. https://www.esri.com/news/releases/12-3qtr/carl-steinitz-explains-geodesign-process-innew-esri-press-book.html.

Tjallingii, S. P. (1996). Ecological conditions; strategies and structures in environmental planning. IBN Scientific Contributions 2. IBN-DLO.

van Timmeren, A. (2006). Autonomie \& Heteronomie. Integratie en verduurzaming van essentiële stromen in de gebouwde omgeving. Ph.D. thesis, Eburon Academic Publishers.

van Timmeren, A. (2014). The concept of the urban metabolism (UM). Delft University of Technology, Faculty of Architecture, Department of Urbanism, Chair Environmental Technology \& Design.

Wandl, A. (2019). Territories in between: A cross-case comparison of dispersed urban development in Europe. Delft University of Technology. https://doi.org/10.7480/abe.2019.14.4340.

Zari, M. P., \& Hecht, K. (2020). Biomimicry for regenerative built environments: Mapping design strategies for producing ecosystem services. Biomimetics, 5(2). https://doi.org/10.3390/BIOMIM ETICS5020018.

Open Access This chapter is licensed under the terms of the Creative Commons Attribution 4.0 International License (http://creativecommons.org/licenses/by/4.0/), which permits use, sharing, adaptation, distribution and reproduction in any medium or format, as long as you give appropriate credit to the original author(s) and the source, provide a link to the Creative Commons license and indicate if changes were made.

The images or other third party material in this chapter are included in the chapter's Creative Commons license, unless indicated otherwise in a credit line to the material. If material is not included in the chapter's Creative Commons license and your intended use is not permitted by statutory regulation or exceeds the permitted use, you will need to obtain permission directly from the copyright holder.

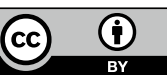

